International Journal of Child, Youth and Family Studies (2013) 2: 209-223

\title{
RELATIVE CONTRIBUTIONS OF ELDER SIBLINGS' VERSUS PARENTS' ACCEPTANCE AND BEHAVIORAL CONTROL TO THE PSYCHOLOGICAL ADJUSTMENT OF YOUNGER SIBLINGS IN TURKEY
}

\author{
Ronald P. Rohner, Azmi Varan, and Nicholas Koberstein
}

\begin{abstract}
This study explores the differential contribution of elder siblings' versus parents' acceptance and behavioral control to the psychological adjustment of younger siblings in Turkey. One hundred eighty younger siblings $(M=12.38$ years $)$ in intact nuclear families with at least one older sibling ( $M=15.79$ years) responded to four selfreports. Results of simple regression analyses showed that younger siblings' perceptions of older siblings', mothers', and fathers' acceptance (but not behavioral control) each made a unique contribution to the psychological adjustment of the younger siblings. Hierarchical regression analyses, however, showed that younger brothers' perceptions of older sisters' acceptance did not make a unique contribution to the boys' adjustment. But all other sibling pairs did contribute uniquely to the adjustment of younger siblings.
\end{abstract}

Keywords: sibling acceptance, parental acceptance, behavioral control, psychological adjustment

Acknowledgement: The authors wish to thank Neşe Ç. Özyavru for her contribution to the data collection process.

Ronald P. Rohner, Ph.D., the Corresponding Author, is Professor Emeritus of Family Studies and Anthropology in the Department of Human Development and Family Studies, University of Connecticut, Unit 2058, 348 Mansfield Road, Storrs, CT, U.S.A., 06269-2058. Telephone: (860) 486-0073, FAX: (860) 486-3452. E-mail: r.rohner@uconn.edu

Azmi Varan, Ph.D. is an Associate Professor of Psychology in the Department of Psychiatry, School of Medicine, Ege University, 35100 Bornova, Izmir, Turkey.

Email: azmi.varan@ege.edu.tr

Nicholas Koberstein is a Ph.D. candidate in the Department of Human Development and Family Studies, University of Connecticut. E-mail: nicholas.koberstein@uconn.edu 
International Journal of Child, Youth and Family Studies (2013) 2: 209-223

Even though a great part of developmental research has focused on parent-child relationships, an emerging literature shows that sibling relationships are also important (Gamble, Yu, \& Kuehn, 2011; Waite, Shanahan, Calkins, Keane, \& O’Brien, 2011). Research in recent decades, for example, has shown that siblings often spend more time with each other than with parents (Waters, 1987). Moreover, it is uncommon for siblings to discontinue their relationship with each other, even if the relational experience has been mostly negative (Cicirelli, 1985; Ross \& Milgram, 1982). Beyond this, siblings often serve as confidantes, teachers, role models, and friends (Cicirelli, 1985), even though close contact often decreases over the lifespan (Pulakos, 1987).

Much of the early work on siblings focused on such structural characteristics of the sibling relationship as age spacing, birth order, and gender composition. However, these early studies tended to show that structural characteristics made only a small contribution to children's development and adjustment. More recent research on sibling relationships has focused on four issues: (a) the developmental course of the sibling relationship over time (Feinberg \& Hetherington, 2000; Kim, McHale, Crouter, \& Osgood, 2007); (b) the link between sibling relations and other family and peer relationships (Bryant, 1992; Milevsky, Schlechter, \& Machlev, 2011); (c) differentiation of siblings (Feinberg, McHale, Crouter, \& Cumsille, 2003; Hetherington, Reiss, \& Plomin, 1994); and, (d) the contributions of the sibling relationship to individual development and adjustment (Hetherington \& Clingempeel, 1992; Krienert \& Walsh, 2011).

Research discussed in this article emphasizes one aspect of the latter issue, specifically the contribution of the sibling relationship to individual psychological adjustment. With respect to that, for example, past research has shown that teaching and caregiving experiences in sibling relationships can benefit both younger and older siblings in terms of emotional, cognitive, language, and psychosocial adjustment and development (Brody, 2004). An overall nurturing sibling relationship often has elements of conflict, however. In fact, a positive sibling relationship is thought by Brody (2004) to contain a balance of both nurturance and conflict. This type of relationship has been shown to provide a basis for healthy psychosocial development, the understanding of emotions, perspective taking, appropriate management of anger, conflictresolution skills, and the ability to be nurturing (Brody, 2004). Sibling conflict, however, can also increase the likelihood that a younger sibling will not receive prosocial and responsive care (McHale \& Crouter, 1996). And children growing up with an aggressive older sibling have been found to have a higher risk of internalizing, externalizing, and conduct disorders among other problems (Bank, Patterson, \& Reid, 1996; Krienert \& Walsh, 2011; Stocker \& Burwell, 2002).

Further, negative feelings originating in the sibling relationship during childhood may persist into adulthood (Ross \& Milgram, 1982). Bank et al. (1996) also noted that chronically high conflict in the sibling relationship may serve as an arena for the development of aggressive behavior, and Campione-Barr and Smetana (2010) reported that sibling conflict was negatively associated with the quality of sibling relationships. On the other hand, research focusing on the benefits of positive and nurturing sibling relationships has been shown to be associated with an increase in the development of social understanding and positive outlook (Dunn, 1999). 
International Journal of Child, Youth and Family Studies (2013) 2: 209-223

Nurturing sibling relationships provide an environment for cooperative pretend play and other opportunities to enhance children's social understanding and peer group interactions (Downey \& Condron, 2004).

The great majority of studies dealing with the impact of sibling relationships on youths' psychological adjustment have been drawn from American samples. Only recently have studies begun to appear from other nations (Lecce, Pagnin, \& Pinto, 2009; Modestin, Marrer, \& Agarwalla, 2008; Ripoll, Carrillo, \& Castro, 2009). As a result, it is difficult to estimate the extent to which conclusions found in North America can be generalized to other sociocultural systems. The study reported here helps to redress that shortcoming.

More specifically, we tested in Turkey the sibling portion of one of parental acceptancerejection theory's (PARTheory's) central postulates. The postulate states that the psychological adjustment of children everywhere throughout the world - regardless of differences in culture, race, language, gender, or other such defining conditions - is likely to be affected in a specific way (described below in the acceptance-rejection syndrome) when they perceive themselves to be accepted or rejected by their parents, siblings, or other attachment figures. The acceptancerejection syndrome (Rohner, 2004) is composed of two complementary sets of factors. First, it asserts that four classes of accepting-rejecting behaviors appear to universally convey the symbolic message that "my parent, sibling, or other attachment figure loves me (or does not love me - i.e., rejects me)". These behaviors include perceived warmth/affection (or coldness and the lack of affection), indifference/neglect, hostility/aggression, and undifferentiated rejection. Second, the acceptance-rejection syndrome asserts that the psychological adjustment of children and adults (as defined by the following personality dispositions) tends universally to vary directly with the level of perceived acceptance or rejection. In particular, the acceptancerejection syndrome specifies that individuals who perceive themselves to be rejected by attachment figures at any point in life are likely to develop problems with:

1. anger, hostility, aggression, passive aggression, or problems with the management of hostility and aggression;

2. dependence or defensive independence depending on the form, frequency, duration, timing, and intensity of the perceived rejection;

3. negative self-esteem;

4. negative self-adequacy;

5. emotional instability;

6. emotional unresponsiveness; and

7. negative worldview.

Taken together, these seven personality dispositions are used in PARTheory as an overall measure of psychological adjustment. Additionally, perceived rejection by an attachment figure is also expected to be panculturally associated with:

8. anxiety;

9. insecurity; and

10. distorted social-cognitive orientations (mental representations). 
International Journal of Child, Youth and Family Studies (2013) 2: 209-223

The theoretical rationale for including these issues in personality subtheory and the acceptancerejection syndrome is discussed in Rohner (1986, 2004), and elsewhere.

A huge body of data summarized in meta-analyses by Khaleque and Rohner (2002b, 2012a, 2012b) and by Rohner and Khaleque (2010) as well as elsewhere (Rohner \& Britner, 2002) overwhelmingly supports the postulate with respect to the effects of perceived rejection in the parent-child relationship. Strong supportive international evidence is also emerging with respect to perceived acceptance-rejection in adult intimate relationships (Rohner \& Melendez, 2008). The study described here, however, is the first PARTheory-based study to explicitly test for possible international generalizability of the postulate in the context of sibling relationships. More specifically, this study examines the differential contribution of elder siblings' versus parents' acceptance and behavioral control to the psychological adjustment of younger siblings in Turkey.

\section{Methods}

\section{Sample Characteristics}

The sample consisted of 180 younger siblings reflecting on the behavior of their elder siblings along with both their mothers and fathers. Eighty-seven of the younger siblings were females; 91 were males, and two failed to identify their gender. Ninety-four of the elder siblings were females; 86 were males. Younger siblings varied in age from 8 through 17 years $(M=$ 12.38 years, $S D=1.90)$. Elder siblings varied in age from 12 through 18 years $(M=15.79$ years, $S D=1.43)$. Sibling pairs varied in age difference from one to eight years, but on average $(M=$ 3.42 years, $S D=1.68$ ) there was an approximately three-and-a-half year spread between the age of the younger sibling and the older sibling. On average, families of the sibling pairs were middle to low socioeconomic status; $24 \%$ of the mothers and $37 \%$ of the fathers had a high school or more education.

\section{Procedures}

The study was conducted through seven elementary schools and high schools in Izmir, Turkey. Parents of the school children, all of whom lived in intact nuclear families with at least one older or younger sibling, were invited to allow their child to participate in the study. After securing informed consent from parents and assent from the children, the youths responded in school during a single class period to the four questionnaires, described next.

\section{Measures}

Turkish-language versions of four measures were used in this research. These included: (a) the Child version of the Parental Acceptance-Rejection/Control Questionnaire for Mothers (Child PARQ/Control: Mother; Rohner, 2005); (b) the Child version of the Parental AcceptanceRejection/Control Questionnaire for Fathers (Child PARQ/Control: Father; Rohner, 2005); (c) the Elder Sibling Acceptance-Rejection/Control Questionnaire (ESAR/CQ; Rohner, 2008); and (d) the Child version of the Personality Assessment Questionnaire (Child PAQ; Rohner \& Khaleque, 2005). Each of these questionnaires is described more fully below. 
Child Version of the Parental Acceptance-Rejection/Control Questionnaire for Mothers and for Fathers (Child PARQ/Control: Mother and Father). The mother and father versions of the PARQ/Control are almost identical 73-item questionnaires designed to assess children's perceptions of maternal and paternal acceptance and behavioral control, respectively. Both versions consist of five scales. The first four scales (60 items) measure children's perceptions of parental warmth/affection, hostility/aggression, indifference/neglect, and undifferentiated rejection. Undifferentiated rejection refers to children's belief that their parents do not really love them, want them, or care about them without necessarily experiencing any clear behavioral indicators that the parents are truly neglecting, aggressive, or unaffectionate toward them. The fifth scale (13 items) measures perceived parental behavioral control.

Sample items on the acceptance-rejection portion of the Mother version of the measure include: "My mother makes me feel wanted and needed" (perceived warmth/affection); "My mother goes out of her way to hurt my feelings" (perceived hostility/aggression); "My mother ignores me as long as I do nothing to bother her" (perceived indifference/neglect); and, "My mother does not really love me” (perceived undifferentiated rejection). Children respond to items such as these on a four-point Likert scale from (4) "Almost Always True" through (1) "Almost Never True”. Scores on the four acceptance-rejection scales are summed (after reverse scoring the warmth/affection scale to create a measure of perceived parental coldness/lack of affection), producing an overall measure of perceived maternal and paternal acceptance-rejection that ranges from a possible low score of 60 (maximum perceived acceptance) to a possible high score of 240 (maximum perceived rejection). Scores at or above 150 reveal the experience of significantly more caregiver rejection than acceptance.

Analyses of the reliability and validity of the acceptance-rejection portion of the measure show it to be robust in national and cross-cultural research. For example, a meta-analysis of 7,152 respondents within the U.S. and cross-culturally revealed a mean weighted effect size of coefficient alpha aggregated across all versions of the PARQ/Control to be 89 (Khaleque \& Rohner, 2002b). Coefficient alpha of the acceptance-rejection portion of the Turkish measure used in this study were .96 for mothers and .97 for fathers.

Possible scores on the behavioral control scale spread from a low of 13 (minimum behavioral control, or extreme permissiveness) to a high of 52 (maximum behavioral control, or restrictive control). A sample item on this scale says, "My mother wants to control whatever I do”. The scale was designed in such a way that scores between 13 and 26 indicate low/lax control (permissiveness); scores between 27 through 39 indicate moderate behavioral control; and, scores between 46 through 52 indicate strict/restrictive behavioral control.

A meta-analysis of the behavioral control scale in 11 studies cross-culturally (Rohner \& Khaleque, 2003) showed that the mean weighted effect size of the scale aggregated across all versions of the scale and across all samples was .73. Alpha coefficients of the behavioral control scale used in this study were .73 for mothers, and .75 for fathers.

Elder Sibling Acceptance-Rejection/Control Questionnaire (ESAR/CQ). The ESAR/CQ is a newly created measure that mirrors the Child PARQ/Control. It too is a 73-item questionnaire 
International Journal of Child, Youth and Family Studies (2013) 2: 209-223

containing the same items as the Child version of the PARQ/Control. In this case, however, younger siblings reflect on the accepting and behaviorally controlling behaviors of a specific older sibling. The ESAR/CQ contains the same five scales as the PARQ/Control. The first four scales (60 items) measure younger siblings' perceptions of their older siblings' warmth/affection, hostility/aggression, indifference/neglect, and undifferentiated rejection. The fifth scale (13 items) measures younger siblings’ perceptions of their older siblings' behavioral control.

Sample items on the acceptance-rejection portion of the measure include: "My elder sibling says nice things about me" (perceived warmth/affection); "My elder sibling ridicules and makes fun of me (perceived hostility/aggression); "My elder sibling totally ignores me" (perceived indifference/neglect); and "My elder sibling does not really love me” (perceived undifferentiated rejection). Younger siblings respond to items such as these on the same fourpoint Likert scale described for the Child PARQ/Control. Additionally, scores on the four acceptance-rejection scales are summed in the same way as on the Child PARQ/Control, thus creating an overall measure of perceived elder sibling acceptance.

The behavioral control scale is almost identical in structure and content to the Child PARQ/Control. However, items in this scale are phrased to be appropriate for older siblings. For example, one item in the scale states, "My elder sibling is always telling me how I should behave".

Because the ESAR/CQ is newly created, it has little history of evidence about its reliability and validity. However, coefficient alpha on the acceptance-rejection portion of the measure in this sample was .81; alpha coefficient for the behavioral control scale was .76. Moreover, an exploratory factor analysis of the measure produced, as expected, a Rejection factor, an Acceptance factor, a Strict behavioral control factor, and a Permissive behavioral control factor (Varan, 2009). This evidence supports the conclusion that the ESAR/CQ is a reliable measure for use in Turkey.

Child Version of the Personality Assessment Questionnaire (Child PAQ). The Child PAQ is a 42-item questionnaire designed to assess children's self-reports about their overall psychological adjustment. It is composed of seven personality dispositions including: Hostility/ Aggression, Emotional Responsiveness, Dependence or Defensive Independence, Self-Esteem, Self-Adequacy, Emotional Stability, and Worldview. Sample items on the Child PAQ include: "I think about fighting or being mean" (Hostility/Aggression); "I like my parents to make a fuss over me when I'm hurt or sick" (Dependence); "I like myself” (Positive Self-Esteem); "I can compete successfully for things I want" (Positive Self-Adequacy); "It is easy for me to show my friends that I really like them" (Emotional Responsiveness); "It is unusual for me to get angry or upset” (Emotional Stability); and, "I think the world is a good, happy place” (Positive Worldview).

Children respond to items such as these on a four-point Likert scale from (4) "Almost Always True of me” through (1) “Almost Never True of me”. A profile of children’s overall selfreported psychological adjustment is achieved by summing the seven scale-scores after reverse scoring needed items. Scores on the measure can spread from a low of 42, indicating healthy psychological adjustment, to a possible high of 168, indicating serious psychological 
International Journal of Child, Youth and Family Studies (2013) 2: 209-223

maladjustment. The mean weighted alpha coefficient of the PAQ in nine studies internationally was .83 (Khaleque \& Rohner, 2002a). Alpha coefficient of the Turkish version of the Child PAQ in this study was .88. Additional evidence about the reliability and validity of the Child PAQ is provided in Rohner and Khaleque (2005).

Because psychological adjustment is the outcome variable in this research, and because all measures used were self-reported by younger siblings, it is important to document the validity of children's reports about their own psychological adjustment using the PAQ. Here, two external sources of evidence from foster parents and from school social workers and guidance counselors are germane. In the first source, Cournoyer (1989) reported in a sample of 50 foster families that children's PAQ scores correlated strongly $(r=.64, p<.001)$ with foster mothers' reports about the children's behavior and psychological adjustment on the CBCL (Achenbach \& Edelbrock, 1983). Further evidence about the validity of children's self-reports comes from school social workers and guidance counselors in a study by Rohner, Bourque, and Elordi (1996). In that study school professionals informally evaluated the psychological adjustment of 281 school children on a four-point Likert scale from (1) no discernable psychological problem to (4) severe psychological problems. Their evaluations - though informal - correlated significantly $(p<.001)$ with children's reports on the PAQ. Substantial additional evidence regarding the validity of children's self-reports on the PAQ is provided in Rohner and Khaleque (2005).

\section{Results}

Both younger boys and younger girls generally perceived themselves to be accepted by their older siblings, mothers, and fathers. Additionally, younger boys and girls also tended to perceive their older siblings, mothers, and fathers to be moderate in behavioral control.

Moreover, both younger boys and girls tended to self-report healthy psychological adjustment. Finally, we should note that there were no significant gender differences between younger boys and younger girls in any of the major variables included in this study. Accordingly, all further analyses involving younger siblings were pooled across genders. Furthermore, $t$ tests showed that younger siblings tended not to report significant differences in their older brothers' versus older sisters' accepting or behaviorally controlling behaviors. Accordingly, all further analyses involving elder siblings were also pooled across genders.

Table 1 displays intercorrelations among the major variables in this study, as perceived by younger siblings. There one can see that younger siblings' perceptions of their older siblings' acceptance correlated significantly with the psychological adjustment of the younger siblings. This was also true of the younger siblings' perceptions of both maternal and paternal acceptance. Additionally, maternal control (but neither elder sibling nor paternal control) correlated significantly but weakly ( $r=.16)$ with the psychological adjustment of the younger youths. 
International Journal of Child, Youth and Family Studies (2013) 2: 209-223

Table 1. Intercorrelations Among Major Variables, as Perceived by Younger Siblings.

\begin{tabular}{|c|c|c|c|c|c|c|c|}
\hline & 1 & 2 & 3 & 4 & 5 & 6 & 7 \\
\hline \multicolumn{8}{|l|}{ Elder Siblings' } \\
\hline 1. Acceptance & --- & & & & & & \\
\hline 2. Behavioral Control & -.01 & --- & & & & & \\
\hline \multicolumn{8}{|l|}{ Mothers' } \\
\hline 3. Acceptance & $.61^{* * *}$ & .01 & --- & & & & \\
\hline 4. Behavioral Control & -.02 & $.56 * * *$ & .02 & --- & & & \\
\hline \multicolumn{8}{|l|}{ Fathers' } \\
\hline 5. Acceptance & $.41^{* * *}$ & .01 & $.60 * * *$ & -.07 & -- & & \\
\hline 6. Behavioral Control & -.08 & $.57 * * *$ & -.06 & $.57 * * *$ & $-.17^{*}$ & --- & \\
\hline 7. Psychological Adjustment & $.55 * * *$ & .12 & $.55 * * *$ & $.16^{*}$ & $.48^{*}$ & .03 & --- \\
\hline
\end{tabular}

Further inspection of Table 1 reveals that not only were perceived elder sibling and parental acceptance - along with perceived maternal control - correlated significantly with the younger youths' psychological adjustment, but perceived elder sibling, maternal, and paternal acceptance were also significantly correlated with each other. This fact raised the question: What, if any, unique or independent contribution do perceived elder sibling, maternal, or paternal acceptance make to the psychological adjustment of the younger youths? In order to answer this question we computed a simple multiple regression analysis, with perceived elder sibling, maternal, and paternal acceptance as the predictor variables, and younger youths' psychological adjustment as the outcome variable. Results showed that the linear combination of these three predictor variables was significantly related to younger youths' psychological adjustment, $F(3,176)=39.18, p<.001$. The sample multiple correlation was .63, indicating that $40 \%$ of the variance in younger youths' psychological adjustment could be explained by the combination of the three predictors. Results also showed that each of the three predictors accounted for a unique portion of the variance in younger youths' psychological adjustment (elder sibling acceptance, $\beta$ $=.31, t=4.24, p<.001$; maternal acceptance, $\beta=.24, t=2.85, p<.01$; paternal acceptance, $\beta=$ $.21, t=2.81, p<.01)$. 
International Journal of Child, Youth and Family Studies (2013) 2: 209-223

Table 2.

Hierarchical Multiple Regression Analyses Predicting Younger Siblings' Psychological Adjustment from Mother, Father, and Elder Siblings' Acceptance and Behavioral Control.

\begin{tabular}{|c|c|c|c|c|c|c|c|c|}
\hline \multirow[b]{3}{*}{ Predictor } & \multicolumn{8}{|c|}{ Younger Siblings' Psychological Adjustment } \\
\hline & \multicolumn{2}{|c|}{ El Sis - Yng Sis } & \multicolumn{2}{|c|}{ El Bro - Yng Bro } & \multicolumn{2}{|c|}{ El Sis - Yng Bro } & \multicolumn{2}{|c|}{ El Bro - Yng Sis } \\
\hline & $\Delta R^{2}$ & $\beta$ & $\Delta R^{2}$ & $\beta$ & $\Delta R^{2}$ & $\beta$ & $\Delta R^{2}$ & $\beta$ \\
\hline Step 1 & .05 & & .01 & & $.15^{*}$ & & $.11^{\mathrm{t}}$ & \\
\hline $\begin{array}{l}\text { Control } \\
\text { variables }^{a}\end{array}$ & & & & & & & & \\
\hline Step 2 & $.36 * *$ & & $.32 * *$ & & $.31 * * *$ & & $.38 * * *$ & \\
\hline Mother Acceptance & & $.61^{* *}$ & & .05 & & $.41^{* *}$ & & .15 \\
\hline Mother Control & & .17 & & .23 & & .18 & & .05 \\
\hline Father Acceptance & & -.10 & & .20 & & .21 & & $.61^{* *}$ \\
\hline Father Control & & -.02 & & $.39^{t}$ & & .02 & & .07 \\
\hline Step 3 & $.14^{*}$ & & $.11^{\mathrm{t}}$ & & .03 & & $.07 *$ & \\
\hline Elder Sibling Acc & & $.50 * *$ & & $.49 * *$ & & .16 & & $.30 *$ \\
\hline Elder Sibling Control & & -.15 & & .19 & & .13 & & .05 \\
\hline Total $R^{2}$ & $.55^{* * *}$ & & $.43^{* *}$ & & $.48 * * *$ & & $.55^{* * *}$ & \\
\hline$n$ & 40 & & 39 & & 45 & & 50 & \\
\hline
\end{tabular}

Note: El Sis = Elder Sister; Yng Sis = Younger Sister; El Bro = Elder Brother; Yng Bro = Younger Brother .

${ }^{a}$ Control variables are ages of elder sibling and younger sibling.

${ }^{\mathrm{t}} p<.10 .{ }^{*} p<.05 .{ }^{* *} p<.01 .{ }^{* * *} p<.001$.

A hierarchical multiple regression analysis by gender pairs shown in Table 2 (i.e., older sister-younger sister, $n=40$; older brother-younger brother, $n=39$; older sister-younger brother, $n=45$; and older brother-younger sister, $n=50$ ) provides a more nuanced view of the influence of older siblings' acceptance and behavioral control on younger siblings’ psychological adjustment, after controlling for the influence of perceived parental (maternal and paternal) acceptance and sibling age. Results of analyses displayed in Table 2 show that younger siblings' perceptions of their older siblings' behavioral control made no unique contribution to the psychological adjustment of younger siblings in any sibling pair.

Younger siblings’ perceptions of their older siblings’ acceptance, however, did make a significant and unique contribution in every sibling pair except for younger brothers' perceptions of their older sisters' acceptance. For this sibling pair it appears that it was primarily the boys' perceptions of parental (especially maternal) acceptance that was associated with the greatest portion of the unique variance in the younger brothers' psychological adjustment. Finally Table 2 also shows that, collectively, the three classes of variables included in the hierarchical regression 
International Journal of Child, Youth and Family Studies (2013) 2: 209-223

(i.e., sibling age, perceived parental acceptance, and perceived older sibling acceptance) explained from $43 \%$ to $55 \%$ of the variance in the various pairs of younger siblings' psychological adjustment.

\section{Discussion}

This study is the first of its kind to explore the differential contribution of older siblings' versus parents' acceptance and behavioral control to the psychological adjustment of younger siblings. The study is also the first PARTheory study to explicitly test the sibling portion of one of the theory's central postulates. This postulate states that the psychological adjustment of children everywhere throughout the world - regardless of differences in culture, race, language, gender, or other such defining conditions - is likely to be affected in a specific way (described in the acceptance-rejection syndrome) when they perceive themselves to be accepted or rejected by their parents, siblings, or other attachment figures.

As expected from this postulate, results of the initial simple regression analyses on the full sample demonstrate that, overall, each of elder sibling, maternal, and paternal acceptance (but not behavioral control) make a unique contribution to the psychological adjustment of younger siblings. The results become more nuanced, however, when one looks at the relative contribution of older siblings' acceptance to younger siblings' psychological adjustment in different sibling pairs (e.g., older sister-younger sister versus older sister-younger brother). In that context - unlike all other sibling pairs - we find that younger brothers' perceptions of older sisters' acceptance does not make a significant contribution to the psychological adjustment of the brothers over and above the contribution made by parents (especially mothers). We have no explanation at this time for this unexpected result except to caution that all analyses of sibling pairs in this study are based on small sample sizes. Small samples such as these can sometimes make the results of hierarchical regression analyses somewhat unstable. Alternatively, there could be some currently unidentified cultural factors in Turkey that specifically tend to dampen the impact of older sisters' acceptance on the psychological adjustment of younger brothers. A solution to this conundrum awaits further research in Turkey.

Despite this unexpected conclusion, it seems clear that perceived elder sibling acceptance tends overall to be a significant predictor of younger siblings' psychological adjustment. Insofar as this is true, then clinicians, social workers, and others working with children who display the constellation of mental health-related personality characteristics described in the acceptancerejection syndrome should make a point of inquiring about the younger children's relationship with their older siblings as well as with both parents prior to developing any intervention or treatment plan.

Finally, we note that conclusions reached in this study should be interpreted with caution because all information about perceived sibling acceptance, parental acceptance, and psychological adjustment are self-reports. We cannot definitively rule out the possibility that shared method variance and response set might be significant contributors to the results. The likelihood that these forms of method bias are primary explanations of the results is reduced, however, by the fact that substantial prior evidence described earlier has shown a convergence of results across a variety of independent sources of measurement of psychological adjustment and 
International Journal of Child, Youth and Family Studies (2013) 2: 209-223

perceived acceptance. Additionally, generalizing from this research should be done with caution in light of the fact that the conclusions are based on evidence about sibling and parental relationships in intact nuclear families. At this time it is unknown if the same results would emerge within the context of other family forms such as extended family households or singleparent households. 
International Journal of Child, Youth and Family Studies (2013) 2: 209-223

\section{References}

Achenbach, T. M., \& Edelbrock, C. (1983). Manual for the child behavior checklist. Burlington: University of Vermont, Department of Psychiatry.

Bank, L., Patterson, G., \& Reid, J. (1996). Negative sibling interaction patterns as predictors of later adjustment problems in adolescent and young adult males. In G. Brody (Ed.), Sibling relationships: Their causes and consequences (pp.197-229). Westport, CT: Ablex Publishing.

Brody, G. (2004). Siblings’ direct and indirect contributions to child development. Current Directions in Psychological Science, 13, 124-126.

Bryant, B. (1992). Sibling caretaking: Providing emotional support during middle childhood. In F. Boer \& J. Dunn (Eds.), Children's sibling relationships: Developmental and clinical issues (pp. 55-69). Hillsdale, NJ: Lawrence Erlbaum Associates, Inc.

Campione-Barr, N., \& Smetana, J. G. (2010). “Who said you could wear my sweater?” Adolescent sibling conflict and associations with relationship quality. Child Development, 81(2), 464-471.

Cicirelli, V. G. (1985). Sibling relationships throughout the life cycle. In L. L’Abate (Ed.), The handbook of family psychology and therapy (pp. 177-214). Homewood, IL: Dorsey Press.

Cournoyer, D. E. (1989). That unloved feeling: Coping with perceived maternal rejection. Dissertation Abstracts International, 49(12-B), 5558.

Downey, D., \& Condron, D. (2004). Playing well with others in kindergarten: The benefit of siblings at home. Journal of Marriage and Family, 66(2), 333-350.

Dunn, J. (1999). Siblings, friends, and the development of social understanding. In A. W. Collins \& B. Laursen (Eds.), Relationships as developmental contexts (pp. 263-279). Mahwah, NJ: Lawrence Erlbaum Associates, Publishers.

Feinberg, M. E., \& Hetherington, E. M. (2000). Sibling differentiation in adolescence: Implications for behavioral genetic theory. Child Development, 71(6), 1512-1524.

Feinberg, M. E., McHale, S. M., Crouter, A. C., \& Cumsille, P. (2003). Sibling differentiation: Sibling and parent relationship trajectories in adolescence. Child Development, 74(5), 1261-1274.

Gamble, W. C., Yu, J. J., \& Kuehn, E. D. (2011). Adolescent sibling relationship quality and adjustment: Sibling trustworthiness and modeling, as factors directly and indirectly influencing these associations. Social Development, 20(3), 605-623. 
International Journal of Child, Youth and Family Studies (2013) 2: 209-223

Hetherington, E., \& Clingempeel, W. (1992). Coping with marital transitions: A family systems perspective. Monographs of the Society for Research in Child Development, 57(2-3), 1242.

Hetherington, E., Reiss, D., \& Plomin, R. (1994). Separate social worlds of siblings: The impact of nonshared environment on development. Hillsdale, NJ: Lawrence Erlbaum Associates, Inc.

Khaleque, A., \& Rohner, R. P. (2002a). Perceived parental acceptance-rejection and psychological adjustment: A meta-analysis of cross-cultural and intracultural studies. Journal of Marriage and Family, 64(1), 54-64.

Khaleque, A., \& Rohner, R. P. (2002b). Reliability of measures assessing the relation between perceived parental acceptance-rejection and psychological adjustment: Meta-analysis of cross-cultural and intracultural studies. Journal of Cross-Cultural Psychology, 33, 87-99.

Khaleque, A., \& Rohner, R. P. (2012a). Pancultural associations between parental acceptancerejection and psychological adjustment of children and adults: A meta-analytic review of worldwide research. Journal of Cross-Cultural Psychology, 43, 784-800.

Khaleque, A., \& Rohner, R. P. (2012b). Transnational relations between perceived parental acceptance and personality dispositions of children and adults: A meta-analytic review. Personality and Social Psychology Review, 16(2), 103-115.

Kim, J., McHale, S., Crouter, A., \& Osgood, D. (2007). Longitudinal linkages between sibling relationships and adjustment from middle childhood through adolescence. Developmental Psychology, 43(4), 960-973.

Krienert, J. L., \& Walsh, J. A. (2011). My brother's keeper: A contemporary examination of reported sibling violence using national level data, 2000-2005. Journal of Family Violence, 26(5), 331-342.

Lecce, S., Pagnin, A., \& Pinto, G. (2009). Agreement in children’s evaluations of their relationships with siblings and friends. European Journal of Developmental Psychology, 6(2), 153-169.

McHale, S., \& Crouter, A. (1996). The family contexts of children's sibling relationships. In G. Brody (Ed.). Sibling relationships: Their causes and consequences (pp. 173-195). Westport, CT: Ablex Publishing.

Milevsky, A., Schlechter, M. J., \& Machlev, M. (2011). Effects of parenting style and involvement in sibling conflict on adolescent sibling relationships. Journal of Social and Personal Relationships, 28(8), 1130-1148.

Modestin, J., Marrer, K., \& Agarwalla, P. (2008). Parenting and psychopathology in sibling pairs. European Journal of Psychiatry, 22(2), 99-105. 
International Journal of Child, Youth and Family Studies (2013) 2: 209-223

Pulakos, J. (1987). Brothers and sisters: Nature and importance of the adult bond. The Journal of Psychology, 121(5), 521-522.

Ripoll, K., Carrillo, S., \& Castro, J. A. (2009). Relationship between siblings and psychological adjustment in adolescents: Effects of the quality of parent-child relationship. Avances en Psicologia Latinoamericana, 27, 125-142.

Rohner, R. P. (1986). The warmth dimension: Foundations of parental acceptance-rejection theory. Beverly Hills, CA: Sage Publications.

Rohner, R. P. (2004). The parental “acceptance-rejection syndrome”: Universal correlates of perceived rejection. American Psychologist, 59, 827-840.

Rohner, R. P. (2005). Parental Acceptance-Rejection/Control Questionnaire (PARQ/Control): Test manual. In R. P. Rohner \& A. Khaleque (Eds.), Handbook for the study of parental acceptance and rejection (4th ed., pp. 187-226). Storrs, CT: Rohner Research Publications.

Rohner, R. P. (2008). Elder Sibling Acceptance-Rejection/Control Questionnaire. Unpublished manuscript, University of Connecticut at Storrs.

Rohner, R. P., Bourque, S. L., \& Elordi, C. A. (1996). Children's perceptions of corporal punishment, caretaker acceptance, and psychological adjustment in a poor, biracial southern community. Journal of Marriage and the Family, 58(4), 842-852.

Rohner, R. P., \& Britner, P. A. (2002). Worldwide mental health correlates of parental acceptance-rejection: Review of cross-cultural and intracultural evidence. Cross-Cultural Research, 36, 16-47.

Rohner, R. P., \& Khaleque, A. (2003). Reliability and validity of the Parental Control Scale: A meta-analysis of cross-cultural and intracultural studies. Journal of Cross-Cultural Psychology, 34, 643-649.

Rohner, R. P., \& Khaleque, A. (2005). Personality Assessment Questionnaire: Test manual. In R. P. Rohner \& A. Khaleque (Eds.) Handbook for the study of parental acceptance and rejection (4th ed., pp. 107-135). Storrs, CT: Rohner Research Publications.

Rohner, R. P., \& Khaleque, A. (2010). Testing central postulates of parental acceptance-rejection theory (PARTheory): A meta-analysis of cross-cultural studies. Journal of Family Theory and Review, 2, 73-87.

Rohner, R. P., \& Melendez, T. (Eds.). (2008). Parental acceptance-rejection theory studies of intimate adult relationships. [Special Issue]. Cross-Cultural Research, 42. 
International Journal of Child, Youth and Family Studies (2013) 2: 209-223

Ross, H. G., \& Milgram, J. I. (1982). Important variables in adult sibling relationships: A qualitative study. In M. E. Lamb \& B. Sutton-Smith (Eds.), Sibling relationships: Their nature and significance across the lifespan, (pp. 225-249). Hillsdale, NJ: Lawrence Erlbaum Associates, Inc.

Stocker, C. M., \& Burwell, R. A. (2002). Sibling conflict in middle childhood predicts children’s adjustment in early adolescence. Journal of Family Psychology, 16, 50-57.

Waite, E. B., Shanahan, L., Calkins, S. D., Keane, S. P., \& O’Brien, M. (2011). Life events, sibling warmth, and youths' adjustment. Journal of Marriage and Family, 73(5), 902912.

Waters, B. (1987). The importance of sibling relationships in separated families. Australian and New Zealand Journal of Family Therapy, 8, 13-17.

Varan, A. (2009). Cronbach's alphas and factor analysis of the Elder Sibling AcceptanceRejection/Control Questionnaire (ESAR/CQ). Unpublished manuscript, Ege University, Izmir, Turkey. 